\title{
Esteróides anabólicos androgênicos e sua relação com a prática desportiva
}

\author{
Tatiana Sousa Cunha, Nádia Sousa Cunha, Maria José Costa Sampaio Moura, \\ Fernanda Klein Marcondes*
}

Departamento de Ciências Fisiológicas, Faculdade de Odontologia de Piracicaba, Universidade Estadual de Campinas, Piracicaba, São Paulo

*Correspondência:

F. K. Marcondes

Departamento de Ciências Fisiológicas

Faculdade de Odontologia de

Piracicaba - UNICAMP

Av. Limeira, 901

13414-903 - Piracicaba - SP

E-mail: fklein@fop.unicamp.br
Os esteróides anabólicos androgênicos (EAA) são um grupo de compostos naturais e sintéticos formados a partir da testosterona ou um de seus derivados, cuja indicação terapêutica clássica está associada a situações de hipogonadismo e quadros de deficiência do metabolismo protéico. Atuando sobre os receptores androgênicos, modulam de forma indissociável tanto os efeitos androgênicos como os anabólicos. Tais substâncias variam na relação entre a atividade anabólica: androgênica, mas nenhum fármaco atualmente disponivel é capaz de desencadear somente efeitos anabólicos. O primeiro relato da utilização dos EAA com o objetivo de melhorar o desempenho atlético ocorreu em 1954, na Áustria, e, desde então, esta prática tornou-se amplamente difundida. Obviamente, o uso de EAA está fora dos limites competitivos e foi declarado ilegal pelos setores governamentais desportivos nacionais e internacionais. Entretanto, segundo estatísticas do Comitê Olímpico Internacional, realizadas em 2000, os EAA são o grupo de substâncias ergogênicas mais comumente utilizadas no processo de doping. Estudos mostram que altas doses de EAA podem acarretar vários efeitos adversos como atrofia do tecido testicular, tumores hepáticos e de próstata, alterações hepatocelulares, no metabolismo lipídico, de humor e de comportamento. O objetivo do presente trabalho será compilar os dados a respeito dos EAA, envolvendo as perspectivas históricas acerca do tema, a fisiologia e os tipos de EAA atualmente existentes, suas indicações terapêuticas e efeitos adversos resultantes do uso indiscriminado bem como a relação entre o uso de EAA e melhora da performance atlética.

\section{Unitermos}

- Esteróides anabólicos androgênicos

- Exercício físico

- Performance 


\section{INTRODUÇÃO}

\section{Esteróides anabólicos androgênicos}

Hormônio é uma substância química secretada, em pequenas quantidades, na circulação sangüínea e que, transportada até os tecidos-alvos, produz uma resposta fisiológica. Quimicamente, os hormônios são classificados como aminas, proteínas e peptídeos ou esteróides (Costanzo, 1999). Os hormônios esteróides incluem os hormônios adrenocorticais, os metabólitos ativos da vitamina $\mathrm{D}$ e aqueles produzidos pelas gônadas, sendo o colesterol o precursor comum desta classe (Berne, Levy, 2000; Silva et al., 2002).

Os esteróides andrógênicos referem-se aos hormônios sexuais masculinos. O termo androgênico é de origem grega, onde andro significa homem e gennan, produzir. Assim, a definição biológica de um androgênio é qualquer substância que produz especificamente o crescimento das gônadas masculinas. Na espécie humana, existem quatro formas principais de androgênios circulantes: a testosterona (Figura 1), diidrotestosterona (DHT), androstenediona, deidroepiandrosterona (DHEA) e seu derivado sulfatado (DHEAS) (Handa, Price, 2000).

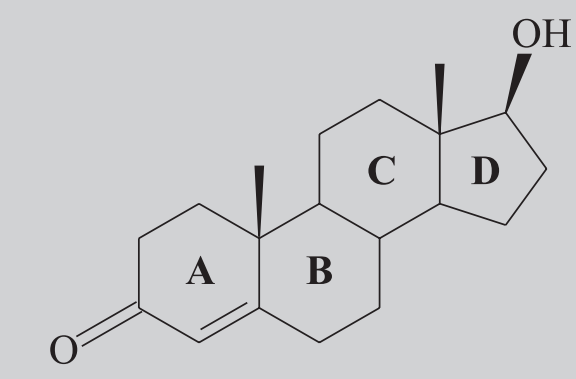

FIGURA 1 - Fórmula estrutural da molécula de testosterona.

As ações da testosterona e dos andrógenos correlatos podem ser divididas em duas categorias principais: efeitos androgênicos, relacionados especificamente com a função reprodutora e com as características sexuais secundárias, e efeitos anabólicos, que dizem respeito, de maneira geral, à estimulação do crescimento e maturação dos tecidos nãoreprodutores. Deve-se salientar que mecanismos intracelulares semelhantes, via um único tipo de receptor, participam destas duas categorias de efeitos, não havendo, portanto, a possibilidade de dissociá-los (Berne, Levy, 2000).

Além dos esteróides androgênicos endógenos, existem os esteróides anabolizantes, ou esteróides anabólicos androgênicos (EAA). Estas substâncias sintéticas, forma- das a partir da testosterona ou um de seus derivados (Lise et al., 1999), são utilizadas na medicina há pelo menos cinco décadas e sua indicação terapêutica está associada a quadros de hipogonadismo e deficiência do metabolismo protéico. Além disso, são amplamente utilizados no meio desportivo com o objetivo de melhorar o desempenho atlético. Assim como os endógenos, também possuem tanto atividade anabólica como androgênica (Silva et al., 2002), sendo que a relação anabólica:androgênica varia de acordo com o tipo de substância utilizada.

\section{PERSPECTIVAS HISTÓRICAS DA RELAÇÃO ENTRE OS EAA E A PRÁTICA DESPORTIVA}

A testosterona foi pela primeira vez sintetizada, em 1935, e, desde então, os andrógenos, tornaram-se disponíveis para utilização com fins terapêuticos e experimentais. Inicialmente, houve pouco interesse por parte dos pesquisadores, na determinação dos efeitos destas substâncias sobre o desenvolvimento, manutenção e restabelecimento da força muscular em indivíduos jovens ou idosos (Samuels et al., 1942; Simonson et al., 1944).

As primeiras evidências da utilização da testosterona com o objetivo de restaurar a "vitalidade" datam de 1889, quando Brown-Séquard relatou retardo no seu processo de envelhecimento após auto-aplicação de um extrato testicular. Este acontecimento estimulou intensa atividade experimental em torno dos hipotéticos efeitos antienvelhecimento da testosterona, antes mesmo que ela tivesse sido isolada (Kuhn, 2002).

Segundo Ryan (1981), durante a Segunda Guerra Mundial, os EAA foram utilizados para restaurar o balanço positivo de nitrogênio em vítimas desnutridas, submetidas a jejum forçado. Lise et al. (1999) relatam ainda que, durante a guerra, as tropas alemãs também fizeram uso destas substâncias com o objetivo de aumentar a agressividade dos seus soldados.

Alguns autores citam que a descoberta de que o uso de hormônios androgênicos poderiam melhorar o desempenho físico ocorreu apenas em 1939 (Thein et al., 1995; Ghaphery, 1995; Scott et al., 1996). Entretanto, Kuhn (2002) relata que tal fato teria ocorrido antes, já em 1896, quando um contemporâneo de Brown-Séquard, após autoadministrar um extrato testicular observou aumento na força muscular do seu dedo.

A primeira utilização dos EAA com o objetivo de melhorar o desempenho de atletas em competição ocorreu em 1954, durante um campeonato de levantamento de pesos em Viena. Os atletas russos que fizeram uso de tais substâncias exibiram performances altamente satisfatórias (Assis, 2002). 
Entretanto, foi no cenário da Guerra Fria que o uso dos EAA atingiu o seu auge. Nos anos 60, a República Democrata Alemã era um país relativamente obscuro associado à imagem da Guerra Fria e circundado pela famosa "Cortina de Ferro". Os políticos do país logo perceberam que o sucesso no esporte seria uma forma rápida e de custo relativamente baixo de fazer com que o país, de 17 milhões de habitantes, fosse reconhecido e recebesse prestígio internacional. Grandes investimentos foram realizados com o objetivo de aprimorar o desempenho atlético, desde sistemáticas triagens de talentos mirins nas escolas até o uso indiscriminado de fármacos ilegais. Todos estes esforços foram organizados de maneira eficiente, com medidas de total segurança para que não fossem descobertos (Franke, Berendonk, 1997). Durante este período, o governo alemão financiou e apoiou, de maneira extremamente sigilosa, o desenvolvimento de inúmeras teses de doutorado sobre os efeitos e danos reversíveis e irreversíveis, decorrentes da administração inspecionada de doses elevadas de EAA e alguns hormônios peptídeos a estudantes e atletas de elite. Os profissionais envolvidos em tais pesquisas (cientistas, médicos e técnicos esportivos) violaram todos os preceitos éticos científicos e médicos. Aos atletas, diziam que estavam recebendo "pílulas de vitaminas" (Turinabol-Oral ${ }^{\circledR}$ ) e, quando era necessária a administração dos EAA através de injeções, diziam que aquelas eram medidas "profiláticas" (ésteres de testosterona e de nandrolona). Os aspirantes a atletas ou atletas profissionais eram orientados a não comentar absolutamente nada a este respeito com os familiares ou amigos (Yesalis, Bahrke, 2000). Em 1968, durante as preparações e treinos para os Jogos Olímpicos, os oficiais da República Democrata Alemã cruzaram outra barreira ética e passaram a administrar hormônios androgênicos em atletas do sexo feminino. A partir de 1972, a pequena República Democrata Alemã esteve constantemente no topo do ranking em contagem de medalhas, juntamente com os EUA e a ex-União Soviética. Assim, os EAA que primeiramente foram utilizados nas modalidades que exigiam força, potência e velocidade, como levantamento de peso, arremessos e lançamentos, natação e corrida de curtas distâncias, passaram a ser também amplamente utilizados nas demais modalidades (Franke, Berendonk, 1997). A partir daí seu uso difundiu-se não só na Alemanha, mas também em outros países do mundo.

A influência de tais substâncias sobre o desempenho atlético de homens (em modalidades que exigiam força) e de mulheres (em praticamente todas as modalidades) foi evidenciada após a introdução de alguns controles antidoping, em 1989, pelo Comitê Olímpico Internacional. Embora os testes fossem imperfeitos e insuficientes, a sua utilização inibiu o uso de EAA. Desde então, muitos atletas jamais conseguiram exibir as marcas alcançadas em competições anteriores. Tal fato ainda é observado, mesmo com o aprendizado e aperfeiçoamento de técnicas para fraudar os exames anti-doping.

A tendência ao declínio de performance não prova que os melhores atletas da atualidade estão livres do doping. Este dado meramente sugere que hoje existe menos doping do que antigamente (Bagatell, Bremner, 1996; Franke, Berendonk, 1997). O uso de tais substâncias ainda faz parte do meio desportivo, competitivo ou não, porque muitos acreditam que a ele também se aplica a lei Darwiniana: somente os mais preparados fisicamente alcançam os níveis mais altos de participação ("Only the fittest reach the highest level of participation"), embora o uso de EAA na seleção natural não seja evidenciado (Norton, Olds, 2001).

\section{Fisiologia dos esteróides androgênicos}

No organismo masculino, a testosterona é o esteróide sexual endógeno mais abundante, a ponto de ser considerada o hormônio testicular fundamental. Cerca de 95\% da testosterona circulante é secretada pelos testículos e apenas 5\%, pelas glândulas supra-renais. A concentração de testosterona na circulação sangüínea é cerca de dez vezes maior do que a de DHT (Handa, Price, 2000), sendo esta mais potente do que a própria testosterona (Marques et al., 2003). Na mulher, estes hormônios também são produzidos, entretanto em menores quantidades, pelas glândulas supra-renais.

No homem, as células testiculares secretoras de testosterona são denominadas células intersticiais de Leydig e são estimuladas pelo hormônio luteinizante (LH) hipofisário. Desta forma, a quantidade de testosterona secretada aumenta aproximadamente em proporção direta à quantidade de LH disponível. A testosterona, secretada pelos testículos em resposta ao $\mathrm{LH}$, exerce efeito recíproco de inibir diretamente a secreção de LH pela hipófise anterior. Porém, a maior parte dessa inibição resulta do efeito direto da testosterona sobre o hipotálamo, diminuindo a secreção do hormônio liberador de gonadotropinas (GnRH). Isso, por sua vez, causa diminuição correspondente da secreção de LH e de hormônio folículo-estimulante (FSH) pela hipófise anterior. Toda vez que a secreção de testosterona está alta, esse efeito automático de retroalimentação negativa, operando através do hipotálamo e da hipófise anterior, reduz a secreção de testosterona para o nível desejado. Por outro lado, quando há baixas concentrações plasmáticas de testosterona, o hipotálamo é estimulado a secretar maior quantidade de GnRH, com aumento 
correspondente na secreção de LH e de FSH, e conseqüente aumento da secreção testicular de testosterona. O FSH, secretado pela hipófise anterior, liga-se a receptores específicos de FSH nas células de Sertoli dos túbulos seminíferos. Essa ligação determina o crescimento das células de Sertoli, que passam a secretar várias substâncias espermatogênicas. Simultaneamente a testosterona e a DHT, ao se difundirem das células de Leydig testiculares para o interior dos túbulos seminíferos, também exercem efeito trófico sobre a espermatogênese. Por conseguinte, para iniciar a espermatogênese, tanto o FSH quanto a testosterona são necessários (Guyton, Hall, 1997).

A testosterona e seus derivados circulam livremente na corrente sangüínea ou ligados a uma proteína plasmática. Quando atingem a célula-alvo desligam-se da proteína transportadora e, devido à sua característica lipossolúvel, atravessam com relativa facilidade a bicamada lipídica da membrana plasmática. No citoplasma da célula, interagem com um receptor específico, formando um complexo hormônio-receptor com alta afinidade pelo núcleo celular. O complexo hormônio-receptor atravessa a membrana nuclear e liga-se com avidez a sítios específicos da cromatina nuclear, denominados elementos de resposta a hormônios esteróides. Ocorre, então, a ativação da RNA polimerase, iniciando o processo de transcrição gênica no qual uma fita de RNA mensageiro, complementar àquela de DNA que serviu como molde, será formada. Através da participação do RNA transportador e do RNA ribossômico, a síntese protéica se desenvolve no citosol celular. As proteínas formadas podem ser estruturais, enzimas ou ainda poderão ser secretadas para serem utilizadas por outras células (Wilson, Foster, 1988). Devido a esta cascata de reações que precedem a síntese protéica, as respostas decorrentes da ação dos hormônios androgênicos apresentam um retardo característico (Guyton, Hall, 1997).

Alguns aspectos da especificidade tecidual à ação androgênica são garantidos pela conversão local da testosterona a metabólitos mais ativos ou específicos, como a DHT. A conversão da testosterona a DHT ocorre sob ação de uma enzima citoplasmática denominada $5 \alpha$ redutase. Este composto possui afinidade 6 a 10 vezes maior pelo receptor androgênico do que a própria testosterona (Wu, 1997).

Após penetrar na célula, a testosterona pode ainda sofrer ação da aromatase citoplasmática, sendo convertida a estrogênio. Após a conversão, o produto desta reação (estradiol) liga-se a receptores estrogênicos e este complexo irá interagir com o DNA nuclear, promovendo resposta estrogênica (Wilson, Foster, 1988; Celotti, Cesi, 1992; Lise et al., 1999). Os hormônios estrogênicos são neces- sários para a deposição de tecido ósseo e também para a fusão epifisária ao final da puberdade (Morishima et al., 1995). Desta forma, seria um tanto quanto surpreendente que as ações biológicas androgênicas, extremamente variadas, fossem mediadas por uma única espécie de receptor androgênico, com mecanismo de ação singular, isto é, através da ativação de elementos responsivos em diferentes genes-alvo (McPhaul et al., 1993). Em outras palavras, a testosterona, por si só, é um hormônio chave, mas também atua como um pró-hormônio circulante para diversos outros tecidos específicos, que possuem as enzimas conversoras $5 \alpha$-redutase e aromatase. Portanto, nem todas as ações desencadeadas pela testosterona são mediadas pela molécula de testosterona propriamente dita ou pelos receptores androgênicos (Wu, 1997).

Os hormônios androgênicos são essenciais durante toda a vida do homem. Durante a fase intra-uterina, a testosterona liberada pelo feto é responsável pela diferenciação da genitália externa e interna (efeitos organizacionais). Na presença de testosterona, liberada pela gônada imatura, o sistema wolffiano, precursor dos órgãos sexuais masculinos internos, desenvolve-se, ocorre atrofia das estruturas precursoras dos órgãos sexuais femininos internos (sistema mülleriano), e a genitália externa e interna desenvolvem-se no padrão masculino. A partir do estudo das síndromes clínicas androgênicas, nas quais se observa deficiência da enzima $5 \alpha$-redutase, concluiu-se que a conversão da testosterona em DHT é essencial para o desenvolvimento da genitália externa durante a vida fetal e também para o crescimento secundário capilar durante a vida adulta (Wilson et al., 1993).

Por outro lado, na ausência da testosterona, a genitália desenvolve-se no padrão feminino. Além disso, a testosterona, secretada durante a vida intra-uterina, sob a ação da aromatase, é convertida a estradiol no sistema nervoso central. Isso é determinante para que no homem adulto, o hipotálamo apresente um padrão não-cíclico de secreção de $\mathrm{GnRH}$, ao contrário do que ocorre na mulher. Na puberdade, a testosterona e seus derivados são responsáveis pela ativação da função testicular e desenvolvimento das características sexuais secundárias (efeitos ativacionais) (Carlson, 2002).

Os hormônios masculinos também atuam sobre um grande número de tecidos-alvo não reprodutivos, incluindo os ossos, tecido adiposo, músculo esquelético, cérebro, próstata, fígado e rins. Como existe maior número de receptores para a testosterona nos órgãos sexuais, as respostas androgênicas serão mais intensas do que as anabólicas nestes tecidos. Ao contrário disso, nos músculos cardíaco e esquelético as ações anabólicas serão mais evidentes (Wilson, 1988). 


\section{Tipos de EAA}

Todos os esteróides ditos anabólicos são compostos derivados da testosterona. Atuando sobre os receptores androgênicos, modulam de forma indissociável tanto os efeitos androgênicos como os anabólicos. Tais substâncias variam na relação entre a atividade anabólica:androgênica (Tabela I), mas nenhum fármaco atualmente disponível é capaz de desencadear somente efeitos anabólicos (Clarkson, Thompson, 1997; Lise et al., 1999).

TABELA I - Relação entre ações anabólicas: androgênicas para os EAA

\begin{tabular}{lc}
\hline $\begin{array}{l}\text { Esteróide anabólico } \\
\text { androgênico }\end{array}$ & $\begin{array}{c}\text { Relação } \\
\text { anabólica:androgênica }\end{array}$ \\
\hline Testosterona, metiltestosterona & 1 \\
Metandrostenolona & $2-5$ \\
Oximetolona & 9 \\
Oxandrolona & 10 \\
Nandrolona & 10 \\
Estanozol & 30 \\
\hline
\end{tabular}

A manipulação da molécula original de testosterona para formulação dos EAA (Figura 2) influencia sua farmacocinética, biodisponibilidade e/ou o balanço da atividade androgênica em prol da anabólica (Wilson, Foster, 1988; Korolkovas, Burckhalter, 1988). Algumas das possíveis alterações das propriedades estruturais e farmacocinéticas da testosterona, para ser utilizada como EAA, estão citadas abaixo:

1. Testosterona administrada na forma injetável, através de adesivos transdérmicos ou cremes corporais;

2. Testosterona $17 \beta$-esterificada (ésteres): cipionato de testosterona, propionato, enantato e undecanoato. A esterificação confere ao esteróide maior solubilidade lipídica e retarda a sua liberação para a circulação, prolongando a sua ação. Todos estes compostos, com exceção do undecanoato, devem ser administrados sob a forma injetável. Vale ressaltar que ésteres de nandrolona $17 \beta$-esterificados também são comercialmente disponíveis;

3. 17 $\alpha$-derivados: metiltestosterona, metandrostenolona, nortandrolona, fluoximesterona, danazol, oxandrolona e estanozol. Estes derivados resistem ao metabolismo hepático, portanto são ativos quando administrados por via oral. A modificação está associada a níveis elevados de hepatotoxicidade;

4. Modificações nos anéis $\mathrm{A}, \mathrm{B}$ ou $\mathrm{C}$ da molécula de testosterona: mesterolona, nortestosterona, metenolona, fluoximesterona, metandrostenolona, nortandrolona, danazol, nandrolona e estanozol. Estas modificações conferem grande número de vantagens ao EAA, que incluem: lenta metabolização, afinidade aumentada pelo receptor androgênico (19-nortestosterona) e resistência à aromatização a estradiol (fluoximesterona, 19-nortestosterona). Além disso, os metabólitos, resultantes da ação da $5 \alpha$-redutase sobre a substância, possuem baixa afinidade pelo receptor androgênico (metabólito resultante da ação da $5 \alpha$-redutase sobre a 19-nortestosterona, origina a $7 \alpha-19$-nortestosterona) (Kuhn, 2002).

Dentre os EAA disponíveis comercialmente, o decanoato de nandrolona é um dos EAA mais utilizados no mundo (Kutscher et al., 2002). Foi introduzido no mercado em 1962 como uma preparação anabólica injetável com ação prolongada de até três semanas após administração intramuscular em humanos. A substância ativa é a nandrolona. Comparativamente à testosterona, apresenta maior ação anabólica e menor atividade androgênica (Wilson, 1988). Quando a nandrolona entra na célula, também sofre ação da $5 \alpha$-redutase. Entretanto, o

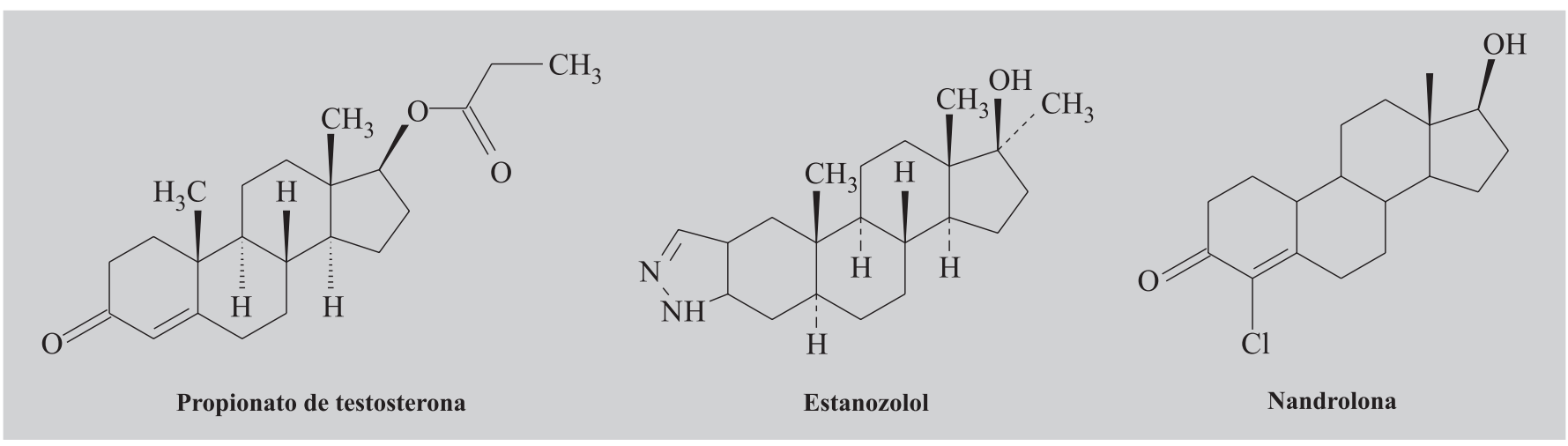

FIGURA 2 - Fórmula estrutural dos EAA. 
metabólito resultante, ao contrário da DHT, tem baixa afinidade pelo receptor androgênico. Esta conversão ocorre em grandes proporções nos órgãos sexuais, devido às altas concentrações da enzima $5 \alpha$-redutase; e, em menor escala, nos músculos esquelético e cardíaco. Assim, os efeitos androgênicos da nandrolona são menores do que os da testosterona. Nos músculos, como a presença de $5 \alpha$ redutase é menor, a própria nandrolona interage com os receptores para esteróides, produzindo respostas anabólicas relativamente maiores (Celotti, Cesi, 1992).

Além disto, a nandrolona é classificada como um androgênio não-aromatizável (Hobbs et al., 1996), o que minimiza, devido a sua baixa taxa de conversão a estrogênio, os efeitos indesejáveis feminilizantes decorrentes da utilização do EAA em doses suprafisiológicas ou por longos períodos (Kuhn, 2002).

\section{Indicações Terapêuticas}

De acordo com a FDA (Food and Drug Administration), há indicação da administração dos EAA no tratamento de hipogonadismo nos homens para aumentar a concentração de testosterona e derivados essenciais ao desenvolvimento e manutenção de características sexuais masculinas. O tratamento com tais substâncias também é recomendado nos casos de puberdade e crescimento retardados, micropênis neonatal, deficiência androgênica parcial em homens idosos e no tratamento da deficiência androgênica secundária a doenças crônicas.

Devido aos seus efeitos anabólicos, os EAA são utilizados em alguns quadros agudos tais como politraumatismos, queimaduras e períodos pós-operatórios, em que os pacientes podem apresentar deficiência no metabolismo protéico (Wilson, 1988; Creutzberg, Schols, 1999).

No tratamento da anemia, por falência da medula óssea, mielofibrose ou doença renal crônica, também há indicação de utilização dos EAA, por estimularem a síntese de epoetina e a eritropoiese e no tratamento da insuficiência renal aguda, por causarem diminuição na produção de uréia, com conseqüente redução do número de diálises necessárias (Ballal et al., 1991; Berns et al., 1992). Além destas aplicações, há associação dos EAA ao tratamento da osteoporose por estimularem os osteoblastos, células responsáveis pela deposição de tecido ósseo (Gordon et al., 1999) e por diminuírem a dor óssea (Lise et al., 1999).

A sua administração em pacientes com síndrome da imunodeficiência adquirida também tem mostrado efeitos satisfatórios assim como no tratamento de certos tipos de neoplasias, pois auxiliam no restabelecimento do peso corporal (Creutzberg, Schols, 1999; Rabkin et al., 2000; Currier, 2000).

\section{Efeitos adversos}

Através de levantamentos epidemiológicos referentes ao uso indiscriminado de EAA, podem-se verificar dados concretos e assustadores acerca do tema, principalmente no que diz respeito ao aumento da taxa de mortalidade entre os usuários de tais substâncias. Como o uso indiscriminado de EAA por atletas profissionais e também por freqüentadores de academias é bastante comum, existe em todo o mundo preocupação sócio-governamental, dentro e fora do meio desportivo (Silva et al., 2002), relacionada a este assunto.

Os efeitos colaterais associados ao uso indiscriminado dos EAA são dose e período-dependentes. No homem, os principais efeitos adversos são: atrofia do tecido testicular, causando infertilidade e impotência, tumores de próstata, ginecomastia, devido à maior quantidade de hormônio androgênico convertido a estrogênio, pela ação da aromatase; dificuldade ou dor para urinar e hipertrofia prostática. Na mulher, manifesta-se a masculinização, evidenciada pelo engrossamento de voz e crescimento de pêlos no corpo no padrão de distribuição masculino; irregularidade menstrual e aumento do clitóris (Wu, 1997). Outras alterações, comuns a ambos os sexos, que também podem manifestar-se são: calvície, aparecimento de erupções acnéicas; fechamento epifisário prematuro, aumento da libido; ruptura de tendão, devido ao aumento exagerado de massa muscular sem equivalente desenvolvimento do tecido tendinoso (Johnson, 1985; Yesalis et al., 1993); alterações no metabolismo lipídico, aumentando os níveis de LDL (lipoproteína de baixa densidade) e diminuindo os de HDL (lipoproteína de alta densidade) (Kuipers et al., 1991).

Além disso, a utilização de tais substâncias está associada a um tipo de tumor de fígado, conhecido como peliose hepática, cuja evolução resulta em hemorragia neste órgão que pode ser fatal (Stimac et al., 2002). Baseando-se também nos níveis elevados das transaminases séricas aspartato aminotransferase (AST/TGO) e alanina aminotransferase (ALT/TGP), vários estudos demonstraram disfunção hepática secundária à administração de doses excessivas de EAA (Pertusi et al., 2001). Estas enzimas não são órgano-específicas (estão presentes em vários tecidos do organismo), entretanto elevam-se mais freqüentemente em pacientes com alterações hepáticas, podendo refletir dano ao fígado, razão pela qual vários autores as denominam enzimas hepáticas (Mincis, 2001). Embora a administração intramuscular de EAA tenha se mostrado menos lesiva para o tecido hepático do que a oral, Saborido et al. (1993) relataram que a aplicação intramuscular de doses excessivas de EAA em ratos, por 
oito semanas, associado ou não à prática de exercício físico, modifica a capacidade hepática de metabolização de outros fármacos, sem afetar indicadores clássicos de disfunção hepática, como AST/TGO e ALT/TGO.

Outra ressalva deve ser feita a respeito da utilização das transaminases AST/TGO e ALT/TGP para diagnosticar disfunção hepática decorrente da administração de doses suprafisiológicas de EAA. Já está bem estabelecido que a prática de exercício físico resistido de alta intensidade também pode aumentar as concentrações séricas destas transaminases (Halbe, 2001); geralmente os protocolos experimentais propostos para estas análises associam doses excessivas de EAA com exercício físico intenso. Desta forma, os níveis séricos elevados das transaminases podem ser decorrentes dos efeitos lesivos provocados pelo exercício e não em razão de danos hepáticos. Pertusi et al. (2001) e Dickerman et al. (1999) sugerem que nestes casos seja realizada também a dosagem de outras duas enzimas: a gama-glutamiltranspeptidase (GGT) para diagnóstico específico de lesão hepática e a creatina-quinase (CK) para diagnóstico exclusivo de lesão muscular.

Alterações hematológicas, decorrentes do abuso de EAA, também podem ser observadas, como mudanças do tempo de coagulação. Os EAA estimulam a eritropoiese através do aumento da síntese de epoetina, podendo causar policitemia e aumento do hematócrito, o que pode favorecer a formação de trombos e aumentar os riscos de ocorrência de acidente vascular cerebral isquêmico (AVCi). Além disso, podem alterar a imunidade humoral, através da diminuição dos níveis das imunoglobulinas IgG, IgM e IgA (Dawson, 2001).

Com relação ao sistema cardiovascular, foi relatada a ocorrência de alterações eletrocardiográficas (Stolt et al., 1999), aumento da pressão arterial (Kuipers et al., 1991), cardiomiopatias, infarto agudo do miocárdio e embolia (Wu, 1997), efeitos colaterais decorrentes do abuso dos EAA (Fineschi et al., 2001). Em coelhos não treinados, o tratamento com decanoato de nandrolona causou diminuição da ação vasodilatadora da acetilcolina (Ferrer et al., 1994a) e da resposta contrátil da aorta (Ferrer et al., 1994b).

Em animais de laboratório também foram observadas alterações comportamentais (Minkin et al., 1993). Na espécie humana, alterações de humor (Gruber, Pope Jr, 2000) e de comportamento (Bahrke et al., 2000) e a ocorrência de suicídio em indivíduos com predisposição genética foram também associadas ao uso de altas concentrações de EAA (Thiblin et al., 1999).

Existem vários relatos a respeito do fenômeno de dependência que o uso de altas doses de EAA pode causar. Este efeito foi pela primeira vez apresentado na lite- ratura médica em 1980 e desde então vários outros estudos envolvendo atletas apresentaram evidências de que os EAA causam dependência física e que, após a sua retirada, há manifestação da síndrome de abstinência (Parssinen, Seppala, 2002).

\section{EAA e desempenho físico}

Um recurso ergogênico é qualquer fator ou fenômeno que aprimora o desempenho, não apenas atlético, mas também emocional e psíquico para a realização do trabalho físico (Powers, Howley, 2000). Com freqüência, os recursos ergogênicos são considerados somente agentes farmacológicos (como os EAA), consumidos com a finalidade de proporcionar alguma vantagem física ao atleta. Entretanto, existem outras classes que incluem componentes nutricionais (carboidratos, proteínas, vitaminas, minerais, água e eletrólitos); fisiológicos (oxigênio, reforço por dopagem sangüínea, condicionamento e procedimentos de recuperação); psicológicos (hipnose, sugestão e ensaio) e mecânicos (mecânica corporal aprimorada, vestimenta, equipamento e treinamento das habilidades) (Foss, Keteyian, 2000).

Alguns recursos ergogênicos são claramente aceitos como coadjuvantes capazes de aprimorar o desempenho e a segurança do atleta. Elementos como treinamento e condicionamento, uso de água, melhores equipamentos, sobrecarga de carboidratos, suplementos vitamínicos e de ferro, técnicas de aquecimento e de volta à calma, e estratégias com ensaios repetidos estão dentro do espírito da competição (Foss, Keteyian, 2000). Obviamente, o uso de EAA e outros agentes farmacológicos está fora dos limites competitivos, e foi declarado ilegal pelos setores governamentais desportivos nacionais e internacionais. Entretanto, segundo estatísticas do Comitê Olímpico Internacional, realizadas em 2000, os EAA são o grupo de substâncias ergogênicas mais utilizadas no processo de doping (Parssinen, Seppala, 2002).

Segundo Dawson (2001), podemos dividir os usuários de EAA em quatro grupos:

1. Aqueles que estão seriamente envolvidos com o esporte e vêem o uso de EAA como uma forma de alcançar melhor rendimento ou de evitarem o "pior", ou seja, a derrota (Wagner, 1989);

2. Aqueles que recentemente se envolveram com o esporte, ou que já praticam exercício físico há algum tempo, mas não têm o objetivo de se tornarem atletas profissionais. Acreditam que a administração de tais substâncias faz parte do meio no qual estão inseridos, ou que esta é a forma mais rápida para melhorar a aparência física ou a performance atlética; 
3. Usuários ocupacionais, como seguranças, policiais ou prisioneiros. Possuem um objetivo bem definido: acreditam que em função da posição que ocupam necessitam aumentar a massa muscular e a agressividade, tanto para proteger como agredir outras pessoas;

4. Usuários recreacionais, que utilizam estas substâncias para aumentar a libido, agressividade ou a sensação de bem-estar. O uso de drogas ilícitas também é bastante comum neste grupo.

Algumas considerações a respeito do uso de EAA pelos grupos 1 e 2 (envolvimento com a prática de atividade física, seja de maneira profissional ou amadora) devem ser mencionadas. Segundo Wu (1997), o uso de EAA por estes indivíduos apóia-se nas seguintes evidências:

1. Diferencial nítido de performance atlética entre homens e mulheres;

2. Diferença de massa magra média entre homens e mulheres, sendo que homens apresentam massa magra $30 \%$ superior à das mulheres;

3. Efeitos anabólicos evidentes resultantes do aumento fisiológico dos níveis de testosterona durante a puberdade;

4. Inquestionáveis efeitos benéficos da administração de doses fisiológicas de testosterona a pacientes com hipogonadismo;

5. Pressuposto de que doses suprafisiológicas de testosterona, ou de análogos sintéticos mais potentes, são capazes de aumentar a massa muscular e melhorar a performance de homens adultos eugonadais;

6. Ilusão de que efeitos anabólicos podem ser dissociados dos androgênicos, através do uso de agentes "puramente anabólicos".

Para estes usuários, o treinamento físico é realizado com o objetivo de preparar o corpo para a competição ou para melhorar a aparência e não por razões de saúde. O corpo é tratado como mera ferramenta para atingir objetivos. Por isso atletas que exibem aparência física saudável nem sempre possuem saúde. Com base nestas considerações é possível entender porque os usuários de EAA consideram favorável e compensador o risco-benefício resultante de tal prática (Wagner, 1989).

Através de revisões da literatura e análise de alguns trabalhos desenvolvidos com o objetivo de se verificar a relação entre o uso de EAA e a performance física em homens, observa-se que muitos estudos falharam no delineamento experimental e por este motivo, não é de se surpreender que os resultados sejam controversos. As diferenças de resultados podem ser atribuídas ao efeito do EAA aumentando a agressividade e a competitividade, às diferenças quanto à intensidade do treinamento ou dieta $\mathrm{e}$ aos efeitos placebos muito importantes (Wilson, 1988;
Elashoff et al., 1991; Friedl, 2000). Outro fator que pode mascarar os resultados é a variação de sensibilidade dos diferentes grupos musculares à testosterona. No homem, os músculos peitorais e os dos ombros apresentam maior resposta aos hormônios androgênicos do que os músculos dos membros inferiores (Hamilton, 1948). Desta forma, a administração de testosterona ou seus derivados aumenta, em diferentes proporções, a massa muscular das regiões superior e inferior do corpo. A performance em tarefas como levantamento de peso fica aumentada quando comparada com aquelas realizadas pelos membros inferiores. Como esperado, grande parte dos estudos que relatam aumento de força muscular decorrente do uso de EAA, o fazem avaliando exercícios realizados pelos músculos da região superior do corpo (Friedl, 2000). Além disso, o grau de incremento da força muscular, decorrente do uso de EAA, muitas vezes é pequeno. Mudanças na performance da ordem de 1 a $5 \%$ são raramente relevantes estatística ou clinicamente, mas podem representar a margem da vitória para atletas de elite. Por esta razão, cientistas, médicos e atletas podem interpretar os dados do mesmo estudo sob diferentes visões (Kuhn, 2002).

Destaca-se também o fato de que, na maioria dos casos (senão na totalidade), os estudos não podem mimetizar a variedade de fármacos que os atletas costumam utilizar, no processo denominado stacking, ou as mudanças nas doses durante os ciclos de administração dos EAA, programa denominado "pirâmide". As variações individuais com relação às habilidades inatas e motivação também são fatores que dificultam as análises. Estudos essencialmente duplo-cegos são difíceis de serem conduzidos em virtude das evidências clínicas decorrentes da administração dos EAA, como por exemplo o aparecimento de erupções acnéicas (Wu, 1997).

Com relação aos estudos em animais, as controvérsias a respeito dos efeitos dos EAA também estão presentes. A eficácia do uso com objetivo de aumentar a massa muscular foi comprovada em animais treinados, entretanto os leitos musculares também respondem de maneira diferente ao estímulo (Sachs, Leipheimer, 1988; Lewis et al., 1999; Leoty et al., 2001), sendo que os músculos relacionados à reprodução (músculo do bulbo cavernoso e elevador do ânus) são mais responsivos à administração de EAA (Rand, Breedlove, 1992), enquanto que os músculos plantar (Antonio et al., 1999), extensor longo dos dedos e sóleo (Leslie et al., 1991; Tingus, Carlse, 1993) sofrem menores alterações frente à castração ou à administração de androgênios.

Apesar de todos estes problemas quanto ao desenvolvimento do protocolo experimental, é grande o número de trabalhos que relatam alterações bioquímicas e 
anatômicas no tecido muscular, decorrentes da administração de doses suprafisiológicas de EAA (Friedl, 2000). Estudos controlados mostraram que tanto o número de fibras musculares quanto o tamanho individual de cada fibra, aumentam em resposta à administração de EAA (Joubert, Toubin, 1989). Estas respostas são potencializadas pela associação do tratamento ao treinamento físico resistido, visando hipertrofia muscular (Tamaki et al., 2001)

As fibras musculares esqueléticas são multinucleadas. Alguns autores consideram que a hipertrofia resultante do uso de EAA, associado à prática de exercícios resistidos, é decorrente do aumento no número de núcleos musculares (mionúcleos), mantendo constante a relação mionúcleos/volume citoplasmático. A principal fonte de mionúcleos é proveniente da ativação, proliferação e incorporação de células-satélite ao músculo correspondente. Estas, por sua vez, também possuem receptores androgênicos (Doumit et al., 1996; Kuhn, 2002).

Sabe-se que, após lesões musculares, as células-satélite são estimuladas, sendo desencadeado um processo de proliferação das mesmas. Estas fornecerão mionúcleos adicionais com o objetivo de restabelecer o domínio muscular. Tamaki et al. (2001) analisaram, em ratos de laboratório, a atividade mitótica de células musculares através da captação de $\left[{ }^{3} \mathrm{H}\right]$ timidina, nucleotídeo essencial para o processo de proliferação, decorrente da aplicação de um protocolo de treinamento resistido. Observaram que, após a realização de saltos em meio líquido com sobrecarga, a captação muscular de $\left[{ }^{3} \mathrm{H}\right]$ timidina foi significativamente menor em animais tratados com EAA em relação a animais tratados com veículo. A menor captação de timidina indica que não houve necessidade de proliferação celular para reparo tissular. Assim, evidencia-se o papel protetor dos EAA sobre os processos de lesões musculares decorrentes da prática de exercícios resistidos. Além disto, no mesmo estudo, observou-se que os animais tratados com EAA apresentaram maior captação de $\left[{ }^{14} \mathrm{C}\right]$ leucina, aminoácido utilizado no processo de hipertrofia muscular.

É bastante clara a participação dos receptores androgênicos no aumento de síntese protéica e de massa muscular. Sabe-se que homens com função gonadal normal apresentam receptores androgênicos saturados pelos níveis fisiológicos normais de testosterona. Se os efeitos anabólicos e androgênicos são mediados por estes receptores, que se apresentam saturados na presença de níveis fisiológicos de testosterona, nenhum efeito benéfico adicional resultaria da administração de hormônios androgênicos (Kuhn, 2002). Entretanto, doses suprafisiológicas de EAA podem ser efetivas no aumento da massa muscular por estimularem incremento do número de re- ceptores androgênicos sobre os quais os EAA exercerão suas funções, processo denominado up-regulation (Bricout et al., 1994; Doumit et al., 1996; Sheffield-Moore et al., 1999; Kadi et al., 2000).

Biópsias musculares de levantadores de peso que utilizaram EAA revelam aumento da expressão de isoformas embrionárias da miosina, quando comparadas com as biópsias de levantadores não usuários de EAA. Tanto as isoformas quanto o antígeno Leu-9 encontram-se presentes em miotubos em desenvolvimento e núcleos musculares recentemente formados (Kadi et al., 1999a,b, 2000).

Além disso, existem evidências do papel anticatabólico exercido pela administração de doses suprafisiológicas de testosterona ou de seus análogos. Em pacientes com mutação genética do receptor androgênico (receptores não-funcionantes), o tratamento com doses suprafisiológicas de EAA também induz aumento de massa muscular (Tincello et al., 1997). Esse fato é decorrente da ligação do hormônio sexual a receptores de glicocorticóides, o que inibe parcialmente a expressão dos efeitos catabólicos provocados pelos glicocorticóides, uma vez que seus sítios de ação estão ocupados. Dados obtidos através de estudos com animais também confirmam este efeito. Vale ressaltar que, em doses fisiológicas, a afinidade EAA/receptor de glicocorticóide é bastante pequena.

Exercícios resistidos, como o levantamento de peso, estimulam o processo de hipertrofia de maneira eficaz, mas são constantemente associados a danos musculares e aumento nos níveis séricos de creatina quinase (CK) (Paul et al., 1989). A função fisiológica desta enzima é catalisar a conversão de ADP em ATP, a partir da creatina fosfato, um substrato energético encontrado no músculo esquelético. Embora a maior concentração desta enzima esteja no músculo esquelético, ela também pode ser encontrada no cérebro, estômago, bexiga, cólon, útero, próstata, intestino delgado e rim e, quando aumentada no soro, é um importante sinalizador de processos lesivos no tecido muscular esquelético.

Foi demonstrado que, quando os EAA são associados ao treinamento resistido, promovem um efeito estabilizador sobre as membranas das células musculares. Desta forma, há diminuição dos danos musculares, com menor efluxo de CK (Spath Jr. et al., 1974). Tamaki et al. (2001) relacionam as menores concentrações séricas de CK, decorrentes da administração de doses suprafisiológicas de EAA a ratos, ao aumento da capacidade de levantamento de peso, em um protocolo de saltos em meio líquido.

A melhora da performance, decorrente da utilização de EAA, também pode estar relacionada ao aumento das 
reservas energéticas. Sabe-se que as reservas musculares e hepáticas de glicogênio são combustíveis energéticos importantes e imprescindíveis durante a atividade física (van Breda et al., 1993). O exercício físico pode alterar os níveis de reserva de glicogênio, fato evidenciado pelo mecanismo de supercompensação do glicogênio. A testosterona também desempenha papel fundamental no processo de armazenamento deste substrato. Animais castrados apresentam diminuição nas reservas de glicogênio, causada pela redução da função enzimática da glicogênio sintase e aumento da glicogênio fosforilase. A reposição hormonal com doses fisiológicas de testosterona reverte este quadro, estimulando a glicogênese e inibindo a glicogenólise (Ramamani et al., 1999). Desta forma, o uso de doses suprafisiológicas de EAA, associado ao treinamento resistido, também poderia estimular este processo, aumentando as reservas de glicogênio e por conseqüência a performance atlética.

Em um estudo desenvolvido em nosso laboratório foram avaliados, em ratos, os efeitos da associação entre EAA e o treinamento resistido anaeróbio sobre as reservas de glicogênio no fígado e nos músculos esqueléticos sóleo, gastrocnêmio vermelho e branco. Dados ainda não publicados mostram que o tratamento por seis semanas com doses suprafisiológicas do EAA decanoato de nandrolona (Deca-Durabolin ${ }^{\circledR}-5 \mathrm{mg} / \mathrm{kg}, 2$ x por semana) (Norton et al., 2000) não promoveu aumento das reservas teciduais de glicogênio, nos músculos esqueléticos e no tecido hepático, além daquele obtido através da prática de exercício resistido anaeróbio (Cunha, 2004). Sabe-se que os usuários de tais substâncias raramente consomem um único tipo de EAA, pois baseiam-se na crença de que os efeitos são proporcionados pela combinação entre EAA com maior ação androgênica e outros com maior ação anabólica (Kuhn, 2002). Apesar de termos utilizado um único tipo de EAA em nosso estudo, observamos que o incremento significativo nas reservas teciduais de glicogênio foi resultante do treinamento físico empregado e que a participação do EAA, mesmo após a administração de doses excessivas, não foi significativa. Através destes e de outros resultados semelhantes encontrados na literatura e, levando-se em consideração os potenciais riscos que este tipo de tratamento pode acarretar à saúde, questionamos novamente até que ponto os resultados obtidos pelos usuários são realmente compensadores.

Assim, salientamos que, diante dos diferentes protocolos experimentais empregados e dos resultados controversos, não estão claros os impactos que doses suprafisiológicas de EAA podem causar ao organismo e nem a relação exata das mesmas com o exercício físico resistido.

\section{CONCLUSÃO}

Apesar das inúmeras lacunas a respeito da comprovação de ações favoráveis dos EAA sobre o desempenho atlético e do grande número de seus efeitos colaterais, verifica-se que o abuso de tais substâncias é uma prática bastante difundida, tanto pela facilidade de obtenção das mesmas por meios legais ou ilegais como também pela desinformação dos usuários acerca dos reais riscos à saúde. Muitos dos trabalhos presentes na literatura mostram efeitos adicionais sobre a performance promovidos pelos EAA, mas são intensamente questionados quanto à confiabilidade metodológica. No ser humano, isto é particularmente mais importante, uma vez que a motivação à prática de exercício físico também pode mascarar os resultados, admitindo-se equivocadamente, que sejam proporcionados pelo uso de EAA e não pelo exercício propriamente dito. Além disso, observa-se que existe intensa valorização de resultados não significativos, e não se sabe até que ponto existiu o compromisso dos pesquisadores na publicação de resultados insatisfatórios ou negativos decorrentes do uso de EAA. Embora muitos pontos a respeito do tema ainda devam ser elucidados, os efeitos negativos decorrentes da má utilização destas substâncias são bastante claros e podem ser evidenciados pela maior taxa de mortalidade (4,6 vezes maior) entre usuários de EAA do que entre não-usuários. Assim, os dados apresentados reforçam a necessidade de se questionar a existência dos efeitos benéficos resultantes do uso dos EAA sobre a performance, significativamente maiores do que aqueles já obtidos através do treinamento físico.

\section{ABSTRACT}

\section{Anabolic androgenic steroids and the relation to the sportive practice}

Anabolic androgenic steroids (AAS) are a group of natural and synthetic agents formed from testosterone or one of its derivatives, whose classical therapeutic indications are associated to hipogonadism and deficiency of proteic metabolism. Acting on androgenic receptors, they modulate both the androgenic and anabolic effects. These substances vary in their ratio of anabolic:androgenic activity, but to date there is no substance that completely separates these effects, promoting only the anabolic ones. The first recorded use of AAS to improve the athletic performance occurred in 1954, in Austria, and since then this practice became widespread. Obviously, the use of AAS is out of the competitive limits, and was declared illegal by the 
national and international sportive governmental sectors. However, according to statistics of the International Olympic Committee, carried out in 2000, the AAS are the group of ergogenic aids most commonly used in the doping process. Studies show that supra-physiological doses of AAS can cause many adverse effects, such as atrophy of testicular tissue, hepatic and prostatic tumors, hepatocellular damage and alterations on the lipidic metabolism, on the humor and on the behavior. The aim of the present study is to compile the data regarding the $A A S$, involving their historical perspectives, the physiology of $A A S$ and the existing AAS types, their therapeutic indications and the side effects resultant of the abuse of these substances and the relation between the use of $A A S$ and the improvement of athletic performance

UNITERMS: Anabolic androgenic steroids. Physical exercise. Performance.

\section{AGRADECIMENTOS}

Este estudo foi financiado por auxílio-pesquisa concedido a FKM pela Fundação de Apoio a Pesquisa do Estado de São Paulo (FAPESP 02/05427-8). TSC recebeu bolsa CAPES de mestrado.

\section{REFERÊNCIAS BIBILIOGRÁFICAS}

ANTONIO, J.; WILSON, J.D.; GEORGE, F.W. Effects of castration and androgen treatment on androgen-receptor levels in rat skeletal muscles. J. Appl. Physiol., Bethesda, v.87, n.6, p.2016-2019, 1999.

ASSIS, W.S. Efeitos da natação associada ao uso de dois esteróides anabolizantes (estanozolol e decanoato de nandrolona) sobre as fibras musculares oxidativas e glicolíticas do músculo gastrocnêmio de ratos. Rio Claro, 2002. 181p. [Dissertação de Mestrado. Instituto de Biociências. Universidade Estadual Paulista "Júlio de Mesquita Filho"].

BAGATELL, C.J.; BREMNER, W.J. Androgens in menuses and abuses. N. Engl. J. Med., Boston, v.334, n.11, p.707-714, 1996.

BAHRKE, M.S.; YESALIS, C.E.; KOPSTEIN, A.N.; STEPHENS, J. A. Risk factors associated with anabolicandrogenic steroid use among adolescents. Sports Med., Auckland, v.29, n.6, p.397-405, 2000.
BALLAL, S.H.; DOMOTO, D.T.; POLACK, D.C.; MARCIULONIS, P.; MARTIN, K.J. Androgens potentiate the effects of erythropoietin in the treatment of anemia in patients on chronic hemodialysis. Am. J. Kidney Dis., Philadelphia, v.17, n.1, p.29-33, 1991.

BERNE, R.M.; LEVY, M.N. As glândulas reprodutoras. In: BERNE, R.M.; LEVY, M.N. Fisiologia. 4 ed. Rio de Janeiro: Guanabara Koogan, 2000. cap. 52, p.910-956.

BERNS, J.S.; RUDNICK, M.R.; COHEN, R.M. A controlled trial of recombinant human erythropoietin and nandrolone decanoate in the treatment of anemia in patients on chronic hemodialysis. Clin. Nephrol., Munchen-Deisenhofen, v. .37, n.5, p.264-267, 1992.

BRICOUT, V.A.; GERMAIN, P.S.; SERRURIER, B.D.; GUEZENNEC, C.Y. Changes in testosterone muscle receptors: effects of an androgen treatment on physically trained rats. Cell Mol. Biol., Noisy-le-Grand, v.40, n.3, p.291-294, 1994.

CARLSON, N.R. O comportamento reprodutivo. In: CARLSON, N.R. Fisiologia do Comportamento. 7 ed. São Paulo: Manole, 2002. cap. 10 , p.304-338.

CELOTTI, F.; CESI, N. Anabolic Steroids: Areview of their effects on the muscles, of their possible mechanisms of action and of their use in athletics. J. Steroid Biochem. Molec. Biol., Oxford, v.43, n.5, p.469-477, 1992.

CLARKSON, P.M.; THOMPSON, H.S. Drugs and sport Research findings and limitations. Sports Med., Auckland, v.24, n.6, p.366-384, 1997.

COSTANZO, L.S. Fisiologia endócrina. In: COSTANZO, L.S. Fisiologia. Rio de Janeiro: Guanabara Koogan, 1999. cap. 9, p.307-360.

CREUTZBERG, E.C.; SCHOLS, A.M.W.J. Anabolic steroids. Curr. Opin. Clin. Nutr. Metab. Care, New York, v.2, n.3, p.243-253, 1999.

CUNHA, T.S. Efeito do esteróide anabólico androgênico nandrolona sobre o metabolismo do glicogênio em ratos sedentários e treinados. Piracicaba, 2004. 89p. [Dissertação de Mestrado. Faculdade de Odontologia de Piracicaba, Universidade Estadual de Campinas]. 
CURRIER, J.S. How to manage metabolic complications of HIV therapy: what to do while we wait for answers. AIDS Read., v.10, n.3, p.162-169, 2000.

DAWSON, R,T. Drugs in sport - the role of the physician. $J$. Endocrinol., Bristol, v.170, n.1, p.55-61, 2001.

DICKERMAN, R.D.; PERTUSI, R.M; ZACHARIAH, N.Y.; DUFOUR, D.R.; McCONATHY, W.J. Anabolic steroid-induced hepatotoxicity: is it overstated? Clin. J. Sport Med., Philadelphia, v.9, n.1, p.34-39, 1999.

DOUMIT, M.E.; COOK, D.R.; MERKEL, R.A. Testosterone up-regulates androgen receptors and decreases differentiation of porcine myogenic satellite cells in vitro. Endocrinology, Bethesda, v.137, n.4, p.1385-1394, 1996.

ELASHOFF, J.D.; JACKNOW, A.D.; SHAIN, S.G.; BRAUNSTEIN, G.D. Effects of anabolic-androgenic steroids on muscular strength. Ann. Intern. Med., Philadelphia, v.115, n.5, p.387-393, 1991.

FERRER, M.; ENCABO, A.; MARIN, J.; BALFAGON, G. Chronic treatment with the anabolic steroid, nandrolone, inhibits vasodilator responses in rabbit aorta. Eur. J. Pharmacol., Amsterdam, v.252, n.2, p.233-241, 1994a.

FERRER, M.; ENCABO, A.; MARIN, J.; BALFAGON, G. Treatment with the anabolic steroid, nandrolone, reduces vasoconstrictor responses in rabbit arteries. Eur. J. Pharmacol., Amsterdam, v.258, n.1-2, p.103-110, 1994b.

FINESCHI, V.; BAROLDI, G.; MONCIOTTI, F.; PAGLICCI, R.L.; TURILLAZZI, E. Anabolic steroid abuse and cardiac sudden death: a pathologic study. Arch. Pathol. Lab. Med., Northfield, v.125, n.2, p.253-255, 2001.

FOSS, M.L.; KETEYIAN, S.J. Medicamentos e recursos ergogênicos. In: FOSS, M.L.; KETEYIAN, S.J. Bases fisiológicas do exercício e do esporte. Rio de Janeiro: Guanabara Koogan, 2000. cap. 18, p.445-462.

FRANKE, W.W.; BERENDONK, B. Hormonal doping and androgenization of athletes: a secret program of German Democratic Republic government. Clin. Chem., Washington, v.43, n.7, p.1262-1279, 1997.
FRIEDL, K.E. Effect of anabolic steroid use on body composition and physical performance. In: YESALIS, C.E., ed. Anabolic steroids in sport and exercise. Champaign: Human Kinetics, 2000. p.139-174.

GHAPHERY, N.A. Performance-enhancing drugs. Orthop. Clin. North Am., Philadelphia, v.26, p.3, p.433-442, 1995.

GORDON, C.M.; GLOWACKI, J.; LeBOFF, M.S. DHEA and the skeleton (through the ages). Endocrine, Totowa, v.11, n.1, p.1-11, 1999.

GRUBER, A.J.; POPE JUNIOR, G. Psychiatric and medical effects of anabolic-androgenic steroid use in women. Psychother. Psychosom v.69, n.1, p.19-26, 2000.

GUYTON, A.C.; HALL, J.E. Funções reprodutoras e hormônios masculinos. In: GUYTON, A.C.; HALL, J.E. Tratado de Fisiologia Médica. 9 ed. Rio de Janeiro: Guanabara Koogan, 1997. cap. 80, p.911-924.

HALBE, W.H. Anabolizantes e substâncias ergogênicas substâncias que aumentam a força muscular. Sinopse Ginecol. Obstet., São Paulo, v.1, n.2, p.58-62, 2001.

HAMILTON, J.B. The role of testicular secretions as indicated by the effects of castration in man and by studies of phatological conditions and the short lifespan associated with maleness. Recent. Prog. Horm. Res., Bethesda, v.3, p.257-322, 1948.

HANDA, J.R.; PRICE, R.H. Androgen Action. In: FINK, G., ed. Encyclopedia of stress. New York: Academic Press, 2000. v.1, p.183-188.

HOBBS, C.J.; JONES, R.E.; PLYMATE, S.R. Nandrolone, a 19-Nortestosterone, enhances insulin-independent glucose uptake in normal men. J. Clin. Endocrinol. Metab., Bethesda, v.81, n.4, p.1582-1585, 1996.

JOHNSON, W.O. Steroids: a problem of huge dimensions. Sports Ilustrated, New York, v.5, n.13, p.38-54, 1985.

JOUBERT, Y.; TOBIN, C. Satellite cell proliferation and increase in the number of myonuclei induced by testosterone in the levator ani muscle of the adult female rat. Dev. Biol., San Diego, v.131, n.2, p.550-557, 1989. 
KADI, F.; BONNERUD, P.;ERIKSSON, A.; THORNELL, L.E. The expression of androgen receptors in human neck and limb muscles: effects of training and selfadministration of androgenic-anabolic steroids. Histochem. Cell Biol., New York, v.113, n.1, p.25-29, 2000 .

KADI, F.; ERIKSSON, A.; HOLMNER, S.; THORNELL, L.E. Effects of anabolic steroids on the muscle cells of strength-trained athletes. Med. Sci. Sports Exerc., Philadelphia, v.31, n.11, p.1528-1534, 1999a.

KADI, F.; ERIKSSON, A.; HOLMNER, S.; BUTLERBROWNE, G.S.; THORNELL, L.E. Cellular adaptation of the trapezius muscle in strength-trained athletes. Histochem. Cell Biol., New York, v.111, n.3, p.189-195, 1999b.

KOROLKOVAS, A.; BURCKHALTER, J.H. Desenvolvimento de fármacos. In:_Química Farmacêutica. Rio de Janeiro: Guanabara Koogan, 1988. cap. 2, p. 39-83.

KUHN, C.M. Anabolic Steroids. Recent. Prog. Horm. Res., Bethesda, v.57, p.411-434, 2002.

KUIPERS, H.; WIJNEN, J.A.; HARTGENS, F.; WILLEMS, S.M. Influence of anabolic steroids on body composition, blood pressure, lipid profile and liver functions in body builders. Int. J. Sports Med., Stuttgart, v.12, n.4, p.413$418,1991$.

KUTSCHER, E.C.; LUND, B.C.; PERRY, P.J. Anabolic steroids: A review for the clinician. Sports Med., Auckland, v.32, n.5, p.285-296, 2002.

LEOTY, C.; HUCHET-CADIOU, C.; TALON, S.; CHOISY, S.; HLEIHEL, W. Caffeine stimulates the reverse mode of $\mathrm{Na} / \mathrm{Ca} 2+$ exchanger in ferret ventricular muscle. Acta Physiol. Scand., Oxford, v.172, n.1, p.2737, 2001.

LESLIE, M.; FORGER, N.G.; BREEDLOVE, S.M. Sexual dimorphism and androgen effects on spinal motoneurons innervating the rat flexor digitorum brevis. Brain. Res., Amsterdam, v.561, n.2, p.269-273, 1991.

LEWIS, M.I.; FOURNIER, M.; YEH, A.Y.; MICEVYCH, P.E.; SIECK, P.M. Alterations in diaphragm contractility after nandrolone administration: an analysis of potential mechanisms. J. Appl. Physiol., Bethesda, v.86, n. 3, p.985-992, 1999 .
LISE, M.L.Z.; GAMA E SILVA, T.S.; FERIGOLO, M.; BARROS, H.M.T. O abuso de esteróides anabólicoandrogênicos em atletismo. Rev. Ass. Med. Bras., São Paulo, v.45, n.4, p.364-370, 1999.

MARQUES, M.A.S.; PEREIRA, H.M.G.; AQUINO NETO, F.R. Controle da dopagem de anabolizantes: o perfil esteroidal e suas regulações. Rev. Bras. Med. Esporte, São Paulo, v.9, n.1, p.1-10, 2003.

McPHAUL, M.J.; MARCELLI, M.; ZOPPI, S.; GRIFFIN, J.E.; WILSON, J.D. The spectrum of mutations in the androgen receptor gene that causes androgen resistence. $J$. Clin. Endocrinol. Metab., Bethesda, v.76, p.17-23, 1993.

MINCIS, M. Interpretação da elevação sérica de enzimas hepáticas em pacientes assintomáticos. Rev. Bras. Med., São Paulo, v.58, n.4, p.38-46, 2001.

MINKIN, D.M.; MEYER, M.E.; VANHAAREN, F. Behavioral effects of long-term administration of an anabolic steroid in intact and castrated male Wistar rats. Pharmacol. Boichem. Behav., Oxford, v.44, n.4, p.959963, 1993.

MORISHIMA, A.; GRUMBACH, M.M.; SIMPSON, E.R.; FISHER, C.; QIN, K. Aromatase deiciency in male and female siblings caused by a novel mutation and the physiological role of estrogens. J. Clin. Endocrinol. Metab., Bethesda, v.80, n.12, p.3689-3698, 1995.

NORTON, G.R.; TRIFUNOVIC, B.; WOODIWISS, A.J. Attenuated beta-adrenoceptor-mediated cardiac contractile responses following androgenic steroid administration to sedentary rats. Eur. J. Appl. Physiol., New York, v.81, n.4, p.310-316, 2000.

NORTON, K.; OLDS, T. Morphological evolution of athletes over the $20^{\text {th }}$ century: causes and consequences. Sports Med., Auckland, v.31, n.11, p. 763-783, 2001.

PARSSINEN, M.; SEPPALA, T. Steroid use and long-term health risks in former athletes. Sports Med., Auckland, v.32, n.2, p.83-94, 2002.

PAUL, G.L.; DELANY, J.P.; SNOOK, J.T.; SEIFERT, J.G.; KIRBY, T.E. Serum and urinary markers of skeletal muscle tissue damage after weight lifting exercise. Eur. J. Appl. Physiol. Occup. Physiol., New York, v.58, n.7, p.786-790, 1989. 
PERTUSI, R.; DICKERMAN R.D.; McCONATHY, W.J. Evaluation of aminotransferase elevations in a bodybuilder using anabolic steroids: hepatitis or rhabdomyolysis? J. Am. Osteopath. Assoc., Bethesda, v.101, n.7, p.391-394, 2001.

POWERS, S.K.; HOWLEY, E.T. Auxílios Ergogênicos. In: POWERS, S.K. \& HOWLEY, E.T. Fisiologia do Exercício-Teoria e Aplicação ao Condicionamento e ao Desempenho. 3 ed. São Paulo: Manole, 2000. cap. 25, p. 463-480.

RABKIN, J.G.; WAGNER, G.J.; RABKIN, R. A doubleblind, placebo-controlled trial of testosteone therapy for HIV-positive men with hypogonadal symptoms. Arch. Gen. Pscychiatry, Chicago, v.57, n.2, p.141-147, 2000.

RAMAMANI, A.; ARULDHAS, M.M.; GOVINDARAJULU, P. Differential response of rat skeletal muscle glycogen metabolism to testosterone and estradiol. Can.J. Physiol. Pharmacol., Ottawa, v.77, n.4, p.300-304, 1999.

RAND, M.N.; BREEDLOVE, S.M. Androgen locally regulates rat bulbocavernosus and levator ani size. $J$. Neurobiol., New York, v.23, n.1, p.17-30, 1992.

RYAN, A.J. Anabolic steroids are fool's gold. Fed. Proc., Bethesda, v.40, n.12, p.2682-2688, 1981.

SABORIDO, A.; MOLANO, F.; MEGIAS, A. Effect of training and anabolic-androgenic steroids on drug metabolism in rat liver. Med. Sci. Sports. Exerc., Baltimore, v.25, n.7, p.815-822, 1993.

SACHS, B.D.; LEIPHEIMER, R.E. Rapid effect of testosterone on striated muscle activity in rats. Neuroendocrinology, Basel, v.48, n.5, p.453-458, 1988.

SAMUELS, L.T.; HENSCHEL, A.F.; KEYS, A. Inflence of methyl testosterone on muscular work and creatine metabolism in normal young men. J. Clin. Endocrinol. Metab., Bethesda, v.2, p.649-654, 1942.

SCOTT, D.M.; WAGNER, J.C.; BARLOW, T.W. Anabolic steroid use among adolescents in Nebraska schools. Am. J. Health Syst. Pharm., Bethesda, v.53, n.17, p.20682072, 1996.
SHEFFIELD-MOORE, M; URBAN, R.J.; WOLF, S.E.; JIANG, J.; CATLIN, D.H.; HERNDON, D.N.; WOLFE, R.R.; FERRANDO, A.A. Short-term oxandrolone administration stimulates net muscle protein synthesis in young men. J. Clin. Endocrinol. Metab., Bethesda, v.84, n.8, p.2705-2711, 1999.

SILVA, P.R.P.; DANIELSKI, R.; CZEPIELEWSKI, M.A. Esteróides anabolizantes no esporte. Rev. Bras. Med. Esporte, São Paulo, v.8, n.6, p.235-243, 2002.

SIMONSON, E.; KEARNS, W.M.; ENGER, M. Effects of methyl testosterone treatment on muscular performance and the central nervous system of older men. J. Clin. Endocrinol. Metab., Bethesda, v.4, p.528-534, 1974.

SPATH Jr, J.A.; LANE, D.L.; LEFER, A.M. Protective action of methylprednisolone on the myocardium during experimental myocardial ischemia in the cat. Circ. Res., Dallas, v.35, n.1, p.44-51, 1974.

STIMAC, D.; MILIC, S; DINTINJANA, R.D.; KOVAC, D.; RISTIC, S. Androgenic/Anabolic steroid-induced toxic hepatitis. J. Clin. Gastroenterol., Philadelphia, v.35, n.4, p.350-352, 2002.

STOLT, A.; KARILA, T.; VIITASALO, M.; MANTYSAARI, M.; KUJALA, U.M.; KARJALAINEN, J. QT interval and QT dispersion in endurance athletes and in power athletes using large doses of anabolic steroids. Am. J. Cardiol., New York, v.84, n.3, p.364-366, 1999.

TAMAKI, T.; UCHIYAMA, S.; UCHIYAMA, Y.; AKATSUKA, A. ROY, R.R.; EDGERTON, V.R. Anabolic steroids increase exercise tolerance. Am. J. Physiol.Endocrinol. Metab., Bethesda, v.280, n.6, p.973981, 2001.

THEIN, L.A.; THEIN, J.M.; LANDRY, G.L. Ergogenic aids. Phys. Ther., Alexandria, v.75, n.5, p.426-439, 1995.

THIBLIN, I.; RUNESON, B.; RAJS, J. Anabolic androgenic steroids and suicide. Ann. Clin. Psychiatry., London, v.11, n.4, p.223-231, 1999 . 
TINCELLO D.G.; SAUNDERS, P.T.; HODGINS, M.B.; SIMPSON, N.B.; EDWARDS, C.R.; HARGREAVES, T.B.; WU, FC. Correlation of clinical, endocrine and molecular abnormalities with in vivo responses to highdose testosterone in patients with partial androgen insensitivity syndrome. Clin. Endocrinol., Oxford, v.46, n.4, p.497-506, 1997.

TINGUS, S.J.; CARLSEN, R.C. Effect of continuous infusion of an anabolic steroid on murine skeletal muscle. Med. Sci. Sports Exerc., Baltimore, v.25, n.4, p.485-494, 1993.

van BREDA, E.; KEIZER, H.A.; GEURTEN, P.; van KRANENBURG, G.; MENHEERE, P.P.; KUIPERS, H.; GLATZ, J.F. Modulation of glycogen metabolism of rat skeletal muscles by endurance training and testosterone treatment. Pflug. Arch., New York, v.424, n.3-4, p.294-300, 1993.

WAGNER, J.C. Abuse of drugs used to enhance athletic performance. Am.J. Hosp. Pharm., Bethesda, v.46, n.10, p.2059-2067, 1989.
WILSON, J.D.; FOSTER, D.W. Ação hormonal de esteróides. In: CLARK, J.H.; SCHRADER, W.T.; O'MALLEY, B.W. Williams: Tratado de Endocrinologia. 7 ed. São Paulo: Manole, 1988. v.1, cap. 3, p. 42-95.

WILSON, J.D. Androgen abuse by athletes. Endocr. Rev., Bethesda, v.9, n.2, p.181-199, 1988.

WILSON, J.D.; GRIFFIN, J.E.; RUSSELL, D.W. Steroid 5 alpha-reductase 2 deficiency. Endocr. Rev., Bethesda, v.14, n.5, p.577-593, 1993.

WU, F.C. Endocrine aspects of anabolic steroids. Clin. Chem., Washington, v.43, n.7, p.1289-1292, 1997.

YESALIS, C.E.; BAHRKE, M.S. Doping among adolescent athletes. Best Pract. Res. Clin. Endocrinol. Metab., London, v.14, n.1, p.25-35, 2000.

YESALIS, C.E.; COURSON, S.P.; WRIGHT, J.E. History of anabolic steroid in sport and exercise. In: YESALIS, C.E., ed. Anabolic steroids in sport and exercise. Champaign: Human Kinetics, 1993. p.51-71.

Recebido para publicação em 14 de agosto de 2003. 